\title{
Further evidence on the relationship between dopamine and novelty seeking: a neuroendocrine study
}

Michel Hansenne, Emmanuel Pinto, William Pitchot, Jean Reggers, Gabriele Scantamburlo, Marie Moor, Marc Ansseau

Department of Psychiatry, University of Liège, CHU Sart Tilman (B35), B-4000 Liège, Belgium

\begin{abstract}
In the biosocial model of Cloninger, three major personality dimensions, novelty seeking (NS), harm avoidance (HA), and reward dependence (RD) are dependent on central monoaminergic systems, respectively dopaminergic, serotonergic, and noradrenergic. This study investigated the relationships between these major personality dimensions and growth hormone $(\mathrm{GH})$ responses to both apomorphine and clo-nidine challenge tests in healthy subjects. GH responses to apomorphine were significantly correlated with NS when peak relative values were considered $(r=0.47, P=0.03)$. HA and RD did not show any relationships with the endocrine responses. In contrast, no significant relationship existed between GH responses to clonidine and any of the three temperament dimensions. These results gave another support of the hypothesized link between NS and dopaminergic central neurotransmission. In contrast, the results did not confirm the association between RD and noradrenergic central neurotransmission, probably because RD is poorly validated. This partial confirmation might suggest that the link between personality traits and neurotransmission systems is probably indirect.
\end{abstract}

Keywords: Novelty seeking; Reward dependence; TCI; Apomorphine; Clonidine

\section{Introduction}

Over the past decade, Cloninger and his colleagues have developed a biosocial model of personality based on four temperaments (novelty seeking, harm avoidance, reward dependence, and persistence) and three characters (self-directedness, cooperativeness and self-transcendence; Cloninger, 1986, 1987; Cloninger \& Svrakic, 1997; Cloninger, Svrakic, \& Przybeck, 1993).

According to Cloninger et al. (1993) temperaments refer to automatic emotional responses to experiences which are moderately heritable and stable throughout life. In contrast, characters refer to self-concepts and individual differences in goals and values which are moderately influenced by sociocultural learning and mature in progressive steps. Briefly described, novelty seeking (NS) is defined as the tendency to respond actively to novel stimuli leading to pursuit of rewards and escape from punishment. Harm avoidance (HA) corresponds to the tendency toward an inhibitory response to signals of aversive stimuli that lead to avoidance of punishment and non-reward. Reward dependence (RD) is defined as the tendency for a positive response to signals of reward to maintain or resist behavioral extinction. Persistence $(\mathrm{P})$ is described in terms of perseverance despite frustration and fatigue. Self-directedness (SD) refers to the ability of an individual to control, regulate and adapt his behavior to fit the situation in accord with individually chosen goals and values. Cooperativeness (C) is formulated to account for individual differences in identification with and acceptance of other people. Selftranscendence (ST) is a character associated with spirituality, and refers generally to identification with everything conceived as essential and consequential parts of a unified whole.

The Temperament and Character Inventory (TCI) is a 226-item self-questionnaire developed by Cloninger and his colleagues to assess the seven dimensions of personality (Cloninger, Przybeck, Svrakic, \& Wetzel, 1994). The variances explained by the rotated factors after Promax rotation ranged from $4.4 \%$ to $2.0 \%$, which is $17.7 \%$ to $8.0 \%$ of the total variance in the 25 factors (Cloninger et al., 1993). The dimensions of the TCI are related to those proposed by Zuckerman (Zuckerman \& Cloninger, 1996), and more particularly NS correlated positively with Impulsive Sensation Seeking, HA positively with Neuroticism-Anxiety, and C negatively with AggressionHostility.

According to the biosocial model of Cloninger, monoamine neurotransmitter systems are considered as the bases of fundamental personality traits (Cloninger, 1986, 1987, 1988). Then, the three fundamental temperaments (i.e. NS, HA, and RD) have been associated to a specific central neurotransmitter: NS to low basal dopaminergic activity (low basal firing rates of dopaminergic neurons being associated with postsynaptic supersensitivity and higher NS score, and inversely higher dopaminergic baseline activity being associated with relative postsynaptic downregulation and lower NS score), HA to high serotonergic activity (high HA scores being related to high 5HT release from presynaptic neurons and with postsynaptic 5-HT receptor down-regulation), and RD to low basal noradrenergic activity (low basal firing rate of locus coeruleus being associated with increased postsynaptic 
sensitivity to norepinephrine and higher score on $\mathrm{RD}$, and at the other extreme, low postsynaptic sensitivity being associated with high noradrenergic basal level and lower RD score).

Although this model has been criticized by several authors for its simplicity and its lack of theoretical bases (Eysenck, 1990; Gelder, 1987; Gray, 1987; Liebowitz, 1987; Zuckerman, 1988), many psychometric and neurobiological investigations have described results that contribute to the validation of this model (Cloninger, Przybeck, \& Svrakic, 1991; Hansenne \& Ansseau, 1999; Hansenne, Pitchot, Gonzalez Moreno, Machurot, Reggers, \& Ansseau, 1997; Hennig, Toll, Schonlau, Rohrmann, \& Netter, 2000; Mulder \& Joyce, 1994; Ruegg et al., 1997; Svrakic, Przybeck, \& Cloninger, 1991; Wiesbeck, Mauerer, Thome, Jacob, \& Boening, 1995).

The association between NS and dopaminergic function has been validated in several studies. Wiesbeck et al. (1995) reported a significant correlation between growth hormone (GH) response to apomorphine (a dopaminergic D2 agonist) and novelty seeking scores in a sample of alcohol dependent men. In contrast, harm avoidance and reward dependence were not related to the endocrine response. More recently, Gerra, Zaimovic, Timpano, Zambelli, Delsignore, and Brambilla (2000) have shown that NS scores correlate positively with D2 postsynaptic receptor sensitivity assessed by the bromocriptine challenge test in a sample of healthy subjects. This result is in agreement with a recent study suggesting an association between dopamine D2 receptor binding and the human NS trait in the right insula cortex (Suhara et al., 2001). In contrast, several studies have not validated the theoretical relation between dopaminergic function and NS (Curtin, Walker, Peyrin, Soulier, Badan, \& Schulz, 1997; Limson et al., 1991).

Contradictory results are available concerning the relationship between reward dependence and noradrenergic function. Limson et al. (1991) found no relationship between the CSF norepinephrine metabolite 3-methoxy-4hydroxyphenylglycol (MHPG) and the reward dependence score. In contrast, two studies (Curtin et al., 1997; Garvey, Noyes, Cook, \& Blum, 1996) recently reported a positive association between reward dependence and urinary MHPG.

Hansenne and Ansseau (1998) reported no association between GH response to clonidine (a selective alpha-2 adrenoreceptor agonist) and RD in a sample of depressed inpatients. Moreover, the authors did not find an association between GH response to apomorphine (a dopaminergic D2 agonist) and NS. Therefore, this study did not validate the hypothesized relationship between novelty seeking and reward dependence dimensions and respectively, the dopaminergic and noradrenergic systems. A major limitation of this study was the sample of depressed inpatients. Indeed, since blunted response to apomorphine and clonidine challenge tests are reported in depression (Ansseau et al., 1988; Matussek et al., 1980), the negative results could be linked to the limited range of GH response to pharmacological probes in depressed inpatients. Moreover, subscales of NS and RD were influenced by the affective state of depressed patients (Hansenne, Reggers, Pinto, Kjiri, Ajamieh, \& Ansseau, 1999).

The aim of this study was to replicate the same methodology (Hansenne \& Ansseau, 1998) in a sample of healthy subjects to explore if the negative results obtained in the depressed sample were related or not to the clinical status of the patients. If we find relations consistent with the Cloninger model, that means that the depressive status of the patients played a role in the production of negative results. Therefore, we investigated the relationship between GH response to challenge tests (apomorphine, and clonidine) and the main temperaments from the TCI in a sample of healthy subjects (NS, HA, RD). Apomorphine and clonidine tests could be considered as two interesting tools to investigate respectively, the dopaminergic and the noradrenergic systems. Indeed, apomorphine is an unselective dopamine receptor agonist unfolding its activity mainly at the postsynaptic D2 dopamine receptors. It stimulates GH secretion in humans through dopamine receptors in the hypothalamus (Lal, De La Vega, Sourkes, \& Friesen, 1972), and has been applied in depression (Ansseau et al., 1988; Pitchot, Hansenne, Gonzalez Moreno, \& Ansseau, 1992). The fact that apomorphine acts on the D2 receptor is of interest because Cloninger associated NS with dopaminergic D2 activity (Cloninger, 1986, 1988). On the other hand, clonidine is a selective alpha-2 adrenoreceptor agonist (Starke, 1981) which induces a GH secretion, and has been widely used in psychiatric patients especially in depression (Ansseau et al., 1988; Hansenne, Pitchot, Gonzalez Moreno, Von Frenckell, \& Ansseau, 1992; Matussek et al., 1980). It has been demonstrated that $\mathrm{GH}$ response to clonidine may provide a selective reflection of postsynaptic alpha-2 adrenoreceptor (Siever \& Uhde, 1984). Indeed, in contrast to the presynaptic alpha-2 (autoreceptors) action of clonidine which induces feedback inhibition by norepinephrine on central norepinephrine cell firing and norepinephrine release, GH response to clonidine is mediated by postsynaptic alpha-2 adrenergic receptors in the hypothalamus. Based on the biological foundations of the Cloninger's model, positive relationships between NS and $\mathrm{GH}$ response to apomorphine as well as between $\mathrm{RD}$ and $\mathrm{GH}$ response to clonidine were expected. For a more complete investigation of the link between the temperaments and neurotransmission systems, the 
relationship between serotonergic function and temperaments has been reported elsewhere (Hansenne \& Ansseau, 1999; Hansenne et al., 1997).

\section{Methods}

\subsection{Subjects}

Forty experimentally naive healthy subjects ( 20 women and 20 men, mean age of $32.5 \pm 10.4$ years) recruited among the staff of the University Hospital of Liège (Belgium) participated in the study. They were paid for their participation (10 $000 \mathrm{BEF})$. They all underwent a medical interview to exclude psychiatric or somatic disorders. Moreover, all subjects had a Body Mass Index (BMI) comprised between 20 and 25 (Bray, 1978; Thomas, McKay, \& Cutlip, 1976). The Ethical Committee of the University of Liège Medical School approved the protocol and all subjects gave their informed consent.

\subsection{Temperament assessment}

The subjects completed a French version of the 226-item self-questionnaire TCI within the day following the challenge tests. Cloninger has recommended the translated version of the TCI used in the study. It has been performed by Téhérani and Lépine and validated by Pélissolo and Lépine (1997). The patients were asked to read each item carefully and to answer with a pencil all of them even if they were not completely sure of the answer. After the patients completed the questionnaire, one author (MH) checked if the items had all been filled. All patients filled 'false' for the validity item (I have lied a lot on this questionnaire).

\subsection{Neuroendocrine challenges}

Clonidine and apomorphine tests were performed at 1-day intervals, both after an overnight fast using a procedure previously described (Ansseau et al., 1988). Due to the influence of estrogens on growth hormone secretion (Tulandi, Lal, \& Guyda, 1987), we included only premenopausal women and the challenge tests were performed between the third and the twelfth day of the menstrual cycle. Briefly, at 08:00, a butterfly needle was inserted into a forearm vein. Blood samples of $10 \mathrm{ml}$ were collected $20 \mathrm{~min}$ before and immediately before the injection of clonidine or apomorphine at 08:30. Successive blood samples were collected 20, 40, 60 and 120 min after the injection. Clonidine $(0.15 \mathrm{mg})$, diluted in saline to obtain $20 \mathrm{ml}$, and apomorphine $(0.5 \mathrm{mg})$, diluted in saline to obtain $0.5 \mathrm{ml}$, were injected respectively IV in $10 \mathrm{~min}$ and SC. Blood samples were immediately centrifuged, and plasma was frozen and kept at $-18^{\circ} \mathrm{C}$ until analysis.

Growth hormone was measured with a double antibody radioimmunoassay with intra-assay and inter coefficients of variation of respectively, $13.3 \pm 4.7$ and $14.8 \pm 9.6 \%$ and a detection limit of $0.1 \mathrm{mIU} / \mathrm{ml}$. GH responses to clonidine and apomorphine were assessed by peak values following injection as well as by the area under the curve (AUC) situated between injection (t0) and the last blood sample (t120). Both measures were performed with absolute and relative values (absolute values minus baseline). Since absolute and relative values were highly correlated $(r<0.97)$, only relative values (peak and AUC) were reported here.

Several subjects were rejected from further analysis because their $\mathrm{GH}$ basal values (tO) or their GH values at t20 were higher than $13 \mathrm{mIU} / \mathrm{ml}$. The exclusion of subjects with basal GH value greater than $13 \mathrm{mIU} / \mathrm{ml}$ was recommended by Laakmann (1990) who demonstrated that healthy volunteers with high GH basal value (called prestimulator subjects) responded significantly less to a noradrenergic challenge than healthy volunteers with low basal values. In consequence, the pharmacological assessment was not valid in subjects with high basal values. Moreover, this criterion was usually adopted by our group (Ansseau et al., 1988; Hansenne et al., 1992; Pitchot et al., 1992), as well as by other groups (Checkley, Slade, \& Shur, 1981; Dinan \& Barry, 1990; Meltzer et al., 1984; Siever et al., 1983; Tancer, Stein, \& Uhde, 1993). According to these criteria, 19 (17 women) from the apomorphine challenge and 17 (13 woman) subjects from the clonidine challenge were rejected.

\subsection{Statistical analysis}

The statistical analyses were performed using Statistica (4.5) for Windows (Statsoft, 1993). The relationships between the temperaments from the TCI and GH response clonidine and apomorphine tests were assessed by Pearson's correlation coefficients. 


\section{Results}

The mean temperament scores among the 21 subjects included to apomorphine challenge were: NS $=17.8$ (S.D. =3.7), $\mathrm{HA}=12.9$ (S.D. = 5.7), and RD=13.7 (S.D. = 3.0). Their mean age was 31.5 (S.D. = 9.8). Their GH relative peak values after apomorphine ranged from 0.07 to $53.6 \mathrm{mIU} / \mathrm{ml}$ (mean value: 15.6 , S.D. $=15.4)$. The AUC values ranged from 04 to $2508.5 \mathrm{mIU} \mathrm{min} / \mathrm{ml}$ (mean value $=814.4$, S.D. $=780.6$ ). The mean temperaments scores among the 23 subjects included to clonidine challenge were: $\mathrm{NS}=16.8$ (S.D. $=3.7), \mathrm{HA}=13.5$ (S.D. $=$ 5.7), and $\mathrm{RD}=13.8$ (S.D. = 3.3). Their mean age was 32.9 (S.D. $=10.1)$. GH relative peak values after clonidine ranged from 0.03 to $60.52 \mathrm{mlU} / \mathrm{ml}($ mean value $=18.2$, S.D. $=18.2)$. The AUC values ranged from -131.6 to $4396.4 \mathrm{mIU} \mathrm{min} / \mathrm{ml}$ (mean value= 1135.2, S.D. $=1271.9)$.

Table 1: Pearson correlation coefficients (r) and probability values $(P)$ between growth hormone $(G H)$ response to apomorphine and clonidine tests (AUC and peak relative values) and the personality dimensions

\begin{tabular}{|c|c|c|c|}
\hline & Novelty seeking & Harm avoidance & Reward dependence \\
\hline \multicolumn{4}{|c|}{ GH response to Apomorphine } \\
\hline $\begin{array}{l}\text { Peak values } \\
\text { AUC }{ }^{\text {a values }}\end{array}$ & $\begin{array}{l}r=0.47 ; P=0.03 \\
r=0.40 ; P=0.075\end{array}$ & $\begin{array}{l}r=-0.34 ; P=0.13 \\
r=-0.35 ; P=0.11\end{array}$ & $\begin{array}{l}r=-0.18 ; P=0.43 \\
r=0.21 ; P=0.34\end{array}$ \\
\hline \multicolumn{4}{|c|}{ GH response to Clonidine } \\
\hline $\begin{array}{l}\text { Peak values } \\
\text { AUC }{ }^{\text {a values }}\end{array}$ & $\begin{array}{l}r=-0.03 ; P=0.89 \\
r=-0.04 ; P=0.82\end{array}$ & $\begin{array}{l}r=0.30 ; P=0.17 \\
r=0.27 ; P=0.19\end{array}$ & $\begin{array}{l}r=0.23 ; P=0.28 \\
r=0.25 ; P=0.25\end{array}$ \\
\hline
\end{tabular}

Fig. 1: Correlation between growth hormone $(G H)$ responses to apomorphine (peak relative values) and novelty seeking (NS) scores from the Temperament and Character Inventory (TCI) in healthy subjects.

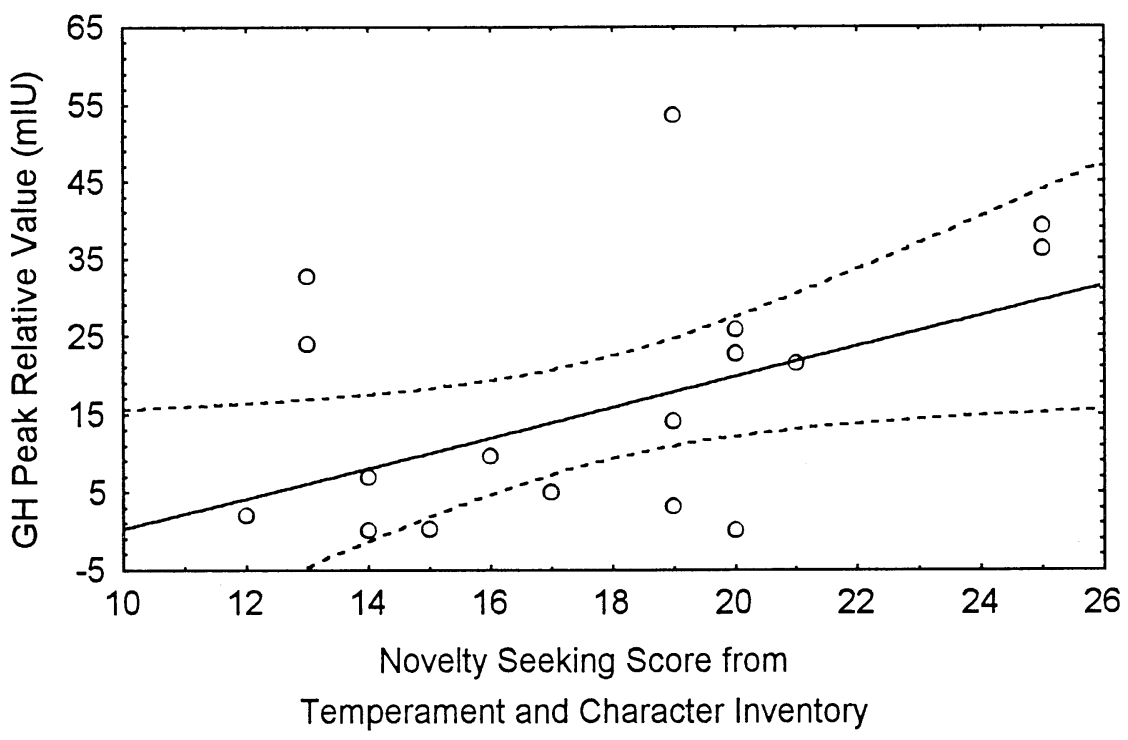

Pearson correlation coefficients and probability values are presented in Table 1. GH responses to apomorphine were significantly correlated with NS when peak relative values were considered $(r=0.47, P=0.03$; Fig. 1$)$. When considering AUC values, the correlation did not reach the statistical level of significance $(r=0.40, P=$ 0.075). HA and RD did not show any relationships with the endocrine responses. In contrast, no significant relationship existed between $\mathrm{GH}$ responses to clonidine and any of the three temperament dimensions.

\section{Discussion}

The main finding of this study is a positive correlation between NS and dopaminergic activity assessed by GH response to apomorphine in healthy subjects. Since apomorphine stimulates GH secretion via dopaminergic D2 postsynaptic receptors located in the hypothalamus, this indicates that NS is related to D2 postsynaptic receptor 
sensitivity, and consecutively related to low dopaminergic activity. It should be noted however that the assumption of decrease presynaptic dopaminergic secretion is more inferential, because the study has not examined the relationship between dopaminergic basal level and response to apomorphine challenge. Nevertheless, the present result supports the theory proposed by Cloninger concerning the link between NS and dopamine (Cloninger, 1986, 1987), and is in agreement with most of the data in the literature.

Indeed, with a similar methodology, Wiesbeck et al. (1995) reported a significant correlation between GH response to apomorphine challenge test and NS among alcoholic subjects. Moreover, Gerra et al. (2000) found a significant direct correlation between NS and bromocriptine-stimulated GH values, and an inverse relationship between NS and bromocriptine-stimulated prolactin values. The authors conclude that NS scores correlate positively with D2 postsynaptic receptor sensitivity and, therefore, with decreased presynaptic dopaminergic secretion. However, Hansenne and Ansseau (1998) did not observe the relationship between NS and dopaminergic responses in a sample of depressed inpatients. This discrepancy may be explained by the fact that the latter study assesses the relationship between NS and dopaminergic activity among depressed patients and that dopaminergic disturbances associated with depression may alter the biological correlates of temperament traits. Therefore, the present relationship between GH response to apomorphine and NS among healthy volunteers is more valid.

However, other negative results were published concerning the relationship between NS dimension and central dopaminergic neurotransmission. Limson et al. (1991) did not find any association between the concentration of cerebrospinal fluid (CSF) homovanillic acid (HVA) and NS scores in alcohol dependent men. Similar negative results were reported in normal subjects (Curtin et al., 1997). These negative results obtained with metabolite data (e.g. HVA) could suggest that the hypothesized association between basal level and receptor sensitivity is not valid. Moreover, recent genetic studies support partially the relationship between NS and dopamine. Whereas some studies have demonstrated that the D4 dopamine receptor gene is associated with NS (Benjamin, Li, Patterson, Greenberg, Murphy, \& Hamer; 1996; Benjamin et al., 2000; Ebstein et al., 1996), others are less conclusive (Samochowiec et al., 2001).

In this present study, RD scores are not correlated with noradrenergic activity, as assessed by the GH response to clonidine. This result does not confirm the link between RD and the noradrenergic system postulated by Cloninger $(1986,1987)$, and is in contrast with those reported by Gerra et al. (2000) who found a positive correlation between RD scores and GH response to clonidine, but replicate the results of a previous study (Hansenne \& Ansseau, 1998). The discrepancy between the present negative finding and the Gerra's et al. results could depend on several factors. First, we used a unique dosage of clonidine $(0.15 \mathrm{mg})$, whereas Gerra et al. injected a weight-related dosage of $2 \mu \mathrm{g}$ clonidine per kg body weight. The choice of a unique dose of clonidine was made according to the fact that the BMI of our patients were within the normal ranges according to the monogram provided by Thomas et al. (1976) and Bray (1978). Second, the blood samples were not collected at the same times $(0,20,40,60$ and 120 min in our study as compared to $0,15,30,45,60$ and 90 min in the Gerra et al. study), which could induce different AUC and peak values. Third, gender was not similar in the two studies: whereas our study was conducted in both sexes, Gerra's et al. study included only men.

Nevertheless, the link between RD and noradrenergic activity is far from clear. Whereas some studies report a positive association between RD and noradrenergic activity assessed by urinary noradrenergic metabolite 3methoxy-4-hydroxyphenylglycol (MHPG) (Curtin et al., 1997; Garvey et al., 1996), Limson et al. (1991) found no relationship between the CSF MHPG and reward dependence score. Moreover, Gerra et al. (2000) reported a significant inverse correlation between RD and the dopaminergic suppression of PRL during the bromocriptine challenge, suggesting that dopaminergic function may also influence this temperament trait. Finally, Tancer, Ranc, and Golden (1994) found a negative correlation between the RD dimension and GH peaks to clonidine test in healthy subjects.

However, given the complexity of the central neurotransmitter systems, these results cannot be considered as definitive evidence against a relationship between noradrenergic activity and the RD dimension defined in the biosocial model of Cloninger $(1986,1987)$. Indeed, if neuroendocrine strategy constitutes a relevant index of central neurotransmission, it exhibits limitations. Clonidine stimulates GH secretion via noradrenergic alpha-2 postsynaptic receptors located in the hypothalamus. It is however postulated that GH response assessed the sensitivity of these postsynaptic receptors. Based on the model of Cloninger, higher postsynaptic activity associated with low noradrenergic basal level, and in consequence higher RD score. Consequently, the negative results of this study must be carefully interpreted and are not simply transferable to the whole noradrenergic system. 
The absence of a relationship between GH response to clonidine and the RD scale could also suggest that RD is a bad scale, even after persistence has been eliminated in the new version. Indeed, RD is very heterogeneous and has a low internal consistency (Cloninger et al., 1991). There are several reason for this. RD has fewer items than NS and HA, and the two subscales with the lower alphas (RD1 and RD4) have only five items. Moreover, the variances of all the RD subscales tend to be smaller. These problems will perhaps be solved with the new version of the TCI (TCI-R) which contains four subscales for RD, including a newer openness to warm communication subscale (10 items).

Before concluding, it is important to underline an important limitation of this study. The two sexes are studied together, whereas hormone and temperament differences were shown. Indeed, HA and RD scales were higher in women than men (Hansenne, Le Bon, Gauthier, \& Ansseau, 2001; Zohar, Lev-Ari, Benjamin, Ebstein, Lichtenberg, \& Osher, 2001). In contrast NS was not different between men and women. In addition, hormone basal levels were different between men and women. For the apomorphine test, 17 women of 20 had a basal GH level higher than $13 \mathrm{mIU} / \mathrm{ml}$. This difference can be explain by the effects of stress, contraception and estrogen. Consequently, it would be preferable to compute the relationship for both sexes separately. However, such analyses were not possible because of the low number of subjects.

In conclusion, this study confirms the relationship between the dopaminergic system and the NS dimension from the model proposed by Cloninger $(1986,1987)$. However, the results do not validate the hypothesized relationship between the RD dimension and the noradrenergic system, but, according to the restrictions mentioned above, these data could not be considered as definitive evidence against the association between RD and specific neurotransmitter substrates.

\section{Acknowledgements}

Special thanks to Anne Couvreur, Xavier Bodeux, and Brigitte Renard for technical assistance.

\section{References}

Ansseau, M., Von Frenckell, R., Cerfontaine, J-L., Papart, P., Franck, G., Timsit-Berthier, M., Geenen, V., \& Legros, J-J. (1988). Blunted response of growth hormone to clonidine and apomorphine in endogenous depression. British Journal of Psychiatry, 153, 65-71.

Benjamin, J., Li, L., Patterson, C, Greenberg, B. D., Murphy, D. L., \& Hamer, D. H. (1996). Population and familial association between the D4 dopamine receptor gene and measures of novelty seeking. Nature Genetics, 12, 81-84.

Benjamin, J., Osher, Y., Kotler, M., Gritsenko, I., Nemanov, L., Belmaker, R. H., \& Ebstein, R. P. (2000). Association between tridimensional personality questionnaire (TPQ) traits and three functional polymorphisms: dopamine receptor D4 (DRD4), serotonin transporter promoter region (5-HTTLPR) and catechol O-methyltransferase (COMT). Molecular Psychiatry, 5, 96-100.

Bray, G. A. (1978). Definition, measurement, and classification of the syndromes of obesity. International Journal of Obesity, 2 , 99-112.

Checkley, S. A., Slade, A. P., \& Shur, E. (1981). Growth hormone and other responses to clonidine in patients with endogenous depression. British Journal of Psychiatry, 138, 51-55.

Cloninger, C. R. (1986). A unified biosocial theory of personality and its role in the development of anxiety states. Psychiatry Developments, $3,167-226$.

Cloninger, C. R. (1987). A systematic method for clinical description and classification of personality variants. Archives of General Psychiatry, 44, 573-588.

Cloninger, C. R. (1988). A unified biosocial theory of personality and its role in the development of anxiety states: a reply to commentaries. Psychiatry Developments, 2, 83-120.

Cloninger, C. R., Przybeck, T. R., \& Svrakic, D. M. (1991). The tridimensional personality questionnaire: US normative data. Psychological Reports, 69, 1047-1057.

Cloninger, C. R., Przybeck, T. R., Svrakic, D. M., \& Wetzel, R. D. (1994). The Temperament and Character Inventory (TCI): a guide to its development and use. St Louis, MO: Center for psychobiology of personality.

Cloninger, C. R., \& Svrakic, D. M. (1997). Integrative psychobiological approach to psychiatric assessment and treatment. Psychiatry, 60, $120-141$.

Cloninger, C. R., Svrakic, D. M., \& Przybeck, T. R. (1993). A psychobiological model of temperament and character. Archives of General Psychiatry, 50, 975-990. 
Curtin, F., Walker, J-P., Peyrin, L., Soulier, V., Badan, M., \& Schulz, P. (1997). Reward dependence is positively related to urinary monoamines in normal men. Biological Psychiatry, 42, 275-281.

Dinan, T. G., \& Barry, S. (1990). Responses of growth hormone to desipramine in endogenous and non-endogenous depression. British Journal of Psychiatry, 156, 680-684.

Ebstein, R. P., Novick, O., Umansky, R., Priel, B., Osher, Y., Blaine, D., Bennett, E. R., Nemanov, L., Katz, M., \& Belmaker, R. H. (1996). Dopamine D4 receptor (D4DR) exon III polymorphism associated with the human personality trait of novelty seeking. Nature Genetics, 12 , $78-80$.

Eysenck, H. J. (1990). Biological bases of personality. In L. A. Pervin (Ed.), Handbook of personality theory and research (pp. 244-276). New York: Guilford press.

Garvey, M. J., Noyes, R. Jr., Cook, B., \& Blum, N. (1996). Preliminary confirmation of proposed link between reward-dependence traits and norepinephrine. Psychiatry Research, 65, 61-64.

Gelder, M. G. (1987). Discussions arising from: Cloninger CR. A unified biosocial theory of personality and its role in the development of anxiety states. Psychiatric Developments, 4, 387-391.

Gerra, G., Zaimovic, A., Timpano, M., Zambelli, U., Delsignore, R., \& Brambilla, F. (2000). Neuroendocrine correlates of temperamental traits in human. Psychoneuroendocrinology, 25, 479-496.

Gray, J. A. (1987). Discussions arising from: Cloninger CR. A unified biosocial theory of personality and its role in the development of anxiety states. Psychiatric Developments, 4, 377-385.

Hansenne, M., \& Ansseau, M. (1998). Catecholaminergic function and temperament in major depressive disorder: a negative report. Psychoneuroendocrinology, 23, 477-483.

Hansenne, M., \& Ansseau, M. (1999). Harm avoidance and serotonin. Biological Psychology, 51, 77-81.

Hansenne, M., Le Bon, O., Gauthier, A., \& Ansseau, M. (2001). Belgian normative data of the temperament and character inventory. European Journal of Psychological Assessment, 17, 56-62.

Hansenne, M., Pitchot, W., Gonzalez Moreno, A., Machurot, P-Y., Reggers, J., \& Ansseau, M. (1997). The harm avoidance dimension of the tridimensional personality questionnaire and 5-HT1A activity in depression. Biological Psychiatry, 42,959-961.

Hansenne, M., Pitchot, W., Gonzalez Moreno, A., Von Frenckell, R., \& Ansseau, M. (1992). Clonidine test and MMPI scales in major depression. European Psychiatry, 7, 129-133.

Hansenne, M., Reggers, J., Pinto, E., Kjiri, K., Ajamieh, A., \& Ansseau, M. (1999). Temperament and character inventory (TCI) and depression. Journal of Psychiatric Research, 33, 31-36.

Hennig, J., Toll, C, Schonlau, P., Rohrmann, S., \& Netter, P. (2000). Endocrine responses after d-fenfluramine and ipsapirone challenge: further support for Cloninger's tridimensional model of personality. Neuropsychobiology, 41, 38-47.

Laakmann, G. (1990). Psychopharmacoendocrinology and depression research. Berlin: Springer-Verlag. Lai, S., De La Vega, S. E., Sourkes, T. L., \& Friesen, H. G. (1972). Effect of apomorphine in human growth hormone secretion. Lancet, ii, 661.

Liebowitz, M. R. (1987). Discussions arising from: Cloninger CR. A unified biosocial theory of personality and its role in the development of anxiety states. Psychiatric Development, 4, 385-387.

Limson, R., Goldman, D., Roy, A., Lamparski, D., Ravitz, B., Adinoff, B., \& Linnoila, M. (1991). Personality and cerebrospinal fluid monoamine metabolites in alcoholics and controls. Archives of General Psychiatry, 48, 437-441.

Matussek, N., Ackenheil, M., Hippius, H., Müller, F., Schröder, H. T., Schultes, H., \& Walislewski, B. (1980). Effect of clonidine on growth hormone release in psychiatric patients and controls. Psychiatry Research, 2, 25-36.

Meltzer, H. Y., Kolakowska, T., Fang, V. S., Fogg, L., Robertson, A., Lewine, R., Strahilevitz, M., \& Busch, D. (1984). Growth hormone response to apomorphine in schizophrenia and the major affective disorders. Archives of General Psychiatry, 41, $512-519$.

Mulder, R. T., \& Joyce, P. R. (1994). Relationships of the tridimensional personality questionnaire to mood and personality measures for depressed patients. Psychological Reports, 75, 1315-1325.

Pélissolo, A., \& Lépine, J.-P. (1997). Traduction française et premières études de validation du questionnaire de personnalité TCI. Annales Médico-Psychologiques, 155, 497-508.

Pitchot, W., Hansenne, M., Gonzalez Moreno, A., \& Ansseau, M. (1992). Suicidal behavior and growth hormone response to apomorphine test. Biological Psychiatry, 31, 1213-1219. 
Ruegg, R. G., Gilmore, J., Ekstrom, R. D., Corrigan, M., Knight, B., Tancer, M., Leatherman, M. E., Carson, S. W., \& Golden, R. N. (1997) Clomipramine challenge responses covary with Tridimensional Personality Questionnaire scores in healthy subjects. Biological Psychiatry, $42,1123-1129$

Samochowiec, J., Rybakowski, F., Czerski, P., Zakrzemska, M., Stepienacute, G., Pelka-Wysiecka, J., Horodnicki, J., Rybakowski, J. K., \& Hauser, J. (2001). Polymorphisms in the dopamine, serotonin and norepinephrine transporter genes and their relationship to temperament and character inventory in healthy volunteers. Neuropsychobiology, 43, 248-253.

Siever, L. J., Insel, T. R., Jimerson, D. C, Lake, C. R., Uhde, T. W., Aloi, J., \& Murphy, D. L. (1983). Growth hormone response to clonidine in obsessive-compulsive patients. British Journal of Psychiatry, 142, 184-187.

Siever, L. J., \& Uhde, T. W. (1984). New studies and perspectives on the noradrenergic receptor system in depression : effects of the alpha-2 adrenergic agonist clonidine. Biological Psychiatry, 19, 131-156.

Starke, K. (1981). Presynaptic receptors. Annual Review of Pharmacology and Toxicology, 21, 7-30.

Statsoft Inc. (1993). Statistica (4.5) for Windows. USA: Tulsa.

Suhara, T., Yasuno, F., Sudo, Y., Yamamoto, M., Inoue, M., Okubo, Y., \& Suzuki, K. (2001). Dopamine d2 receptors in the insular cortex and the personality trait of novelty seeking. Neuroimage, 13, 891-895.

Svrakic, D. M., Przybeck, T. R., \& Cloninger, C. R. (1991). Further contribution to the conceptual validity of the unified biosocial model of personality: US and Yugoslav data. Comprehensive Psychiatry, 32, 195-209.

Tancer, M. E., Ranc, J., \& Golden, R. N. (1994). Pharmacological challenge test of the tridimensional personality questionnaire in patients with social phobias and normal volunteers. Anxiety, 1, 224-226.

Tancer, M. E., Stein, M. B., \& Uhde, T. W. (1993). Growth hormone response to intravenous clonidine in social phobia : comparison to patients with panic disorder and healthy volunteers. Biological Psychiatry, 34, 591-595.

Thomas, A. E., McKay, D. A., \& Cutlip, M. B. (1976). A monograph method for assessing body weight. American Journal of Clinical Nutrition, 29, 302-304.

Tulandi, T., Lai, S., \& Guyda, H. (1987). Effect of estrogen on the growth hormone response to the alpha-adrenergic agonist in women with menopausal flushing. Journal of Clinical Endocrinology and Metabolism, 65, 6-10.

Wiesbeck, G. A., Mauerer, C, Thome, J., Jacob, F., \& Boening, J. (1995). Neuroendocrine support for a relationship between "novelty seeking" and dopaminergic function in alcohol-dependent men. Psychoneuroendocrinology, 20, 755-761.

Zohar, A. H., Lev-Ari, L., Benjamin, J., Ebstein, R., Lichtenberg, P., \& Osher, Y. (2001). The psychometric properties of the Hebrew version of Cloninger's Tridimensional Personality Questionnaire. Personality and Individual Differences, 30, 1297-1309.

Zuckerman, M. (1988). Sensation seeking and behavior disorders. Archives of General Psychiatry, 45, 502-503.

Zuckerman, M., \& Cloninger, C. R. (1996). Relationships between Cloninger's, Zuckerman's, and Eysenck's dimensions of personality. Personality and Individual Differences, 21, 283-285. 